\title{
EFFECTS OF METER ORIENTATION DOWNSTREAM OF A SHORT RADIUS ELBOW ON ELECTROMAGNETIC FLOW METERS
}

Jared C. Justensen, Graduate Engineer, Jones and Demille Engineering, 469 W 400 N, Richfield, Utah, 84701, jared.justensen@gmail.com

Steven L. Barfuss, Research Professor, Utah State University, 8200 Old Main Hill, Logan, Utah, 84322-8200, steve.barfuss@usu.edu

Michael C. Johnson, Research Professor, Utah State University, 8200 Old Main Hill, Logan, Utah, 84322-8200, michael.johnson@usu.edu

Thomas E. Meacham, Independent Consultant, 103 Hart Court, Perkasie, PA, 18944, tem@comcast.net

\begin{abstract}
Electromagnetic flowmeters (known as magnetic flow meters) are a widely used type of flowmeter. This study examines the performance of magnetic flow meters when the electrodes in the meter are positioned at two different orientations: electrodes parallel with the plane of an upstream 90degree short radius elbow and electrodes perpendicular to the plane of an upstream 90-degree short radius elbow. Four different meters from four different manufacturers were included in the study in which a baseline straight pipe test was first performed using over fifty diameters of straight pipe upstream of each meter. The four meters were then installed at five different locations downstream from a 90-degree short-radius elbow. At each location the meters were tested in two orientations at five different flow rates. From this research, shifts in the flow rate were observed with the electrodes located at two different orientations. Theses shifts in flow rate ranged from $0.01 \%$ to $4.40 \%$ of the total flow measurement, and the average shifts in flow rate ranged from $0.07 \%$ to $2.78 \%$. For the purposes of this study, the shift in flow rate is the percentage relative to the baseline test. The results from this
\end{abstract}


research illustrated that there is a significant difference in measurement accuracy when the meter electrodes are installed at different orientations relative to the plane of the bend.

\section{INTRODUCTION}

The ability to measure flow accurately is critical for water users as well as for those providing and selling the water. Magnetic flow meter manufacturers provide guidelines for appropriate meter installations so that the meter maintains manufacturer's stated accuracy. While typical guidelines cover many different conditions, most guidelines do not address the effect on meter accuracy caused by the orientation of the meter.

There have been several studies on the effects of flow disturbances on magnetic flow meters when installed in different orientations. In Luntta's study (Luntta 1998), the distance from a disturbance (pipe bend) as well as the orientation of the meter to the disturbance were evaluated. At various locations downstream of the elbow, the meter was tested at two electrode orientations, electrode axis parallel to the bend plane and electrode axis perpendicular to the bend plane. Luntta found a relationship between the errors that occurred when the meter was rotated and the distance of the meter downstream of the disturbance. The study showed a shift in results when the electrodes where rotated from parallel to the bend plane to perpendicular to the bend plane. The shift was observed at 2 diameters and 10 diameters downstream of the bend having magnitudes of $1.25 \%$ and $0.1 \%$ respectively.

In a Seametrics study (Perry 2014), the difference in results due to different orientations of the meters was studied. Perry stated that the shift was related to the weight function. The weight function is explained as the relation between the shape of the velocity profile and the sensitivity of the electrodes inside the meter (Luntta 1998). In the Seametrics study, Perry states that most magnetic flow meters do not have uniform weight functions (Perry 2014). Essentially, this means that magnetic flow 
meters are sensitive to the location of distortions in the velocity profile. Although Perry was able to find a meter orientation that produced the most accurate results, improving the accuracy from $2.5 \%$ to $0.5 \%$, for the specific magnetic flow meter that was used in his research, he stated that it is unknown if any one meter orientation will produce accurate results for all types of meters (Perry 2014).

The research contained in this study builds upon the results of these previous studies, but focuses on how multiple magnetic flow meters from different manufacturers and with varying accuracy statements, are affected by distance from and relative orientation to an upstream elbow.

\section{OBJECTIVE}

The objective of this paper is to provide data on the effects of meter orientation when the meter is installed downstream of a disturbance. Results produced by the two different meter orientations were compared to each other and to a straight pipe baseline test performed on each meter. Tests at varying lengths from the elbow were performed to more fully understand the effects of orientation on the meter. The results of this paper will provide information to magnetic flow meter users of the potential effects on accuracy that may be expected as a result of different meter installations downstream from 90-degree bends.

\section{METER DESCRIPTIONS}

Magnetic flow meters are capable of providing accurate and repeatable results and are among the most common flow meter types being used today. If the conditions are appropriate for their use, the accuracy of these meters can be within $0.2 \%$ or even better. This is to say that the meter is able to accurately measure the flow rate to within $+/-0.2 \%$ of the actual flow.

Magnetic flow meters operate based on Faraday's Law of Induction. This law states that if a conductor of length I (meters) is moving with a velocity $\mathrm{v}$ (meter per second) perpendicular to a 
magnetic field of flux density B (Tesla), then it induces a voltage e across the ends of a conductor (Thorn 1999). This can be expressed by Eq1:

$$
\mathrm{e}=\mathrm{B} \mid \mathrm{v}
$$

In the case of magnetic flow meters, the conductor is the water moving through the meter and the length of the conductor is the distance between the two electrodes (Thorn 1999). Magnetic coils within the meter create the magnetic field and the electrodes sense the induced voltage. The uniformity of the magnetic field does have a direct effect on the accuracy of the meter when measuring velocity contours in the X-velocity. Four 10 -inches $(254 \mathrm{~mm}$.) magnetic flow meters, each from a different manufacturer were tested during this project. In addition, three of the four meters had different specified accuracies as reported by the manufacturer. The meters also differed in power source (AC or Pulsed DC), the output signal, the specified accuracy of the meter, the minimum velocity at which the manufacturer's stated meter accuracy is valid, the minimum flow at which the manufacturer's stated meter accuracy is valid, the recommended meter orientation from vertical, and the required length of pipe between the meter and the elbow (as defined by the manufacturer). Note that manufacturers often will state that meters should be orientated 45 degrees from vertical to avoid sediment build up and collection of air bubbles near the electrodes.

Each test meter went through a visual inspection. The purpose of the inspection was to measure the dimensions of each meter, and to make note of anything that may differ from meter to meter. Observed meter differences were inside diameter, size of electrodes, and how far the electrode protruded into the flow. Two things of interest were observed during the preliminary comparative evaluation, including; the inside diameter of each of the 10-inches $(254 \mathrm{~mm}$.) meters and how far the electrodes protruded out of the interior meter lining into the flow path. It was first observed that the inside diameter of each of the four 10 -inches $(254 \mathrm{~mm}$.) meters was not only found to be different from 
each other (Meter $A=10.09$ in $(256.9 \mathrm{~mm}$.), Meter $B=9.74$ in $(247.5 \mathrm{~mm}$.$) , Meter \mathrm{C}=8.55 \mathrm{in}(217.2$ $\mathrm{mm}$.), Meter $\mathrm{D}=9.24$ in $(234.8 \mathrm{~mm}$.), but also different than the inside diameter of the 10 -inches (254 mm.) standard wall pipe that was connected to it (test pipe ID was 10-inches). The other interesting difference between the meters was how far the electrodes protruded out of the meter into the flow path (electrode height). The electrode height varied from 0 in to 0.114 in. There are two purposes for designing the flow meter so that the electrodes protrude into the flow stream. The first purpose is to keep the face of the electrode above any coating that could form on the bore of the meter, and the second purpose is to keep the face of the electrode clean by utilizing the higher velocity in the flow stream, as compared to the lower velocities that occur near the pipe wall.

\section{EXPERIMENTAL SETUP AND PROCEDURE}

The pipe setup utilized for the straight pipe tests of this study contained over fifty diameters of straight pipe upstream of the meter under test. As a result of the author's physical and numerical experience with hydraulics in pipelines, this was determined to be a sufficient amount of straight pipe to ensure that the velocity profile was as fully developed as possible at the meter location. Flows of 250 gpm, 1000 gpm, 2000 gpm, 3000 gpm and 4000 gpm were tested during each of the four straight pipe tests. Noteworthy is that magnetic flow meters typically have means of adjusting for bias in the flow measurement, however for the purposes of this study, no adjustments were made to any of the meters to correct for flow measurement bias.

The pipe setup for the elbow tests included a reference meter, then further downstream a short-radius elbow followed by one of five different pipe lengths preceding the meter that was being tested: CC, 1D, 3D, 5D, 10D (Figure 1). The test meter location in this study is defined as the distance between the short-radius elbow and the test meter downstream of the elbow. For example, "CC" denotes the test meter is closed coupled to the short-radius elbow. The other locations are 1D, 3D, 5D, 
and $10 \mathrm{D}$ and refer to $1 \mathrm{D}$ or one pipe diameter $(254 \mathrm{~mm})$ between the short-radius elbow and the test meter, and so forth. As previously mentioned, at each of these five pipe lengths, the test meter was also installed and tested in two orientations. The two orientations included; meter electrodes in plane or parallel (EIP) with the elbow and meter electrodes out of plane or perpendicular (EOP) with the elbow (Figure 2). These two meter-orientations were chosen because they provided the maximum angle of rotation possible between two electrode orientations, therefore potentially illustrating the maximum effect due to electrode orientation. On the downstream side of the test meter there was a pipe segment (greater than $6 \mathrm{D}$ ) followed by a regulating valve. Combinations of each pipe length, meter orientation, and flow rate were tested.

\section{RESULTS}

Figures 3, 4, 5, and 6 show results for the elbow test for all meters at location 3D and 10D, and Figure 7 shows results for the elbow test for meter B at all locations. Figure 7 is provided as an example of a full data set for one meter. The results from the meter B tests were selected because the shift in meter performance from EIP to EOP is clearly seen for meter B. Locations 3D and 10D were selected for Figures $3,4,5$, and 6 , because the $3 \mathrm{D}$ length is a typical upstream straight pipe length requirement from manufacturer specifications for installing magnetic flow meters and 10D is typically the amount of straight pipe required downstream of an elbow to minimize the magnetic flow meter's percent error when installed downstream of an elbow from hydraulic literature (Miller 1996).

The change from EIP to EOP can immediately be seen in each of the figures. The average deviation (percent error) of the straight pipe test data for each meter is also illustrated, and includes results for those velocities that are above the specified minimum velocity for each meter as specified by the manufacturer. Note that the average deviation from the straight pipe test is a +/- (over or underestimation) quantity. The change from EIP to EOP is numerically shown in the figures only for velocities 
of $4 \mathrm{fps}$ and $8 \mathrm{fps}$. The minimum velocity and meter accuracy are also illustrated in the figures as indicated by the meter manufacturer. Table 1 contains the percent deviation shift from EIP to EOP for all velocities at all locations. Table 2 shows the average percent deviation shift from EIP to EOP for all velocities at all locations.

The results from the project show the effects of meter orientation on magnetic flow meter accuracy. By examining the results, it is clear that there is a shift in meter performance when the meters are rotated from EIP to EOP. The authors believe one and perhaps the primary reason for this shift in meter performance is that the electrodes are sensitive to the shape of the velocity profile (Luntta 1998). To better understand this premise, it is necessary to understand how the velocity profile changes downstream of an elbow.

\section{DISCUSSION}

Differences in the $\mathrm{X}$ velocity (longitudinal velocity) profile on the measurement plane will have less effect on the signal voltage when the magnetic system is designed for uniform flow. Considering equation $1, \mathrm{e}=\mathrm{B} \mid \mathrm{V}$. I is fixed by the design and construction of the meter. $\mathrm{B}$ at any location on the measurement plane, is a function of the design of the magnetic system. $V$ at any location on the measurement plane is effected by the upstream disturbance and e is the product of the B I v elements on the measurement plane. Please note in Figure 8, which shows the cross section of the meter with uniform lines of flux and the approximate distribution of Positive and Negative lons. Also consider the absence of charged ions in the middle of the flow path and at locations 90-degrees from the electrode locations. This diagram clearly illustrates that when the velocity profile in the pipe is not uniform, the ability of the meter to accurately measure the flow is diminished.

Other studies have illustrated how the velocity profile downstream of an elbow changes with distance from the disturbance. In one such study, computational fluid dynamics software (Stoker 2011) 
was used to understand this change. Stoker's research modeled a 12-inch (304.8 mm.) diameter pipe downstream of a long-radius elbow with a Reynolds number of 500,000. Stoker tested 3 conditions including: straight pipe, installation one and a half diameters downstream of the elbow and ten diameters downstream of the elbow. The velocity profiles for these conditions are shown in Figures 9, 10 and 11, respectively. The disturbance produced by the elbow is shown on Figures 10 and 11 . As expected, the elbow causes the velocity to be larger on the outside of the elbow and smaller on the inside of the elbow, where swirling and even some negative flow is possible. Magnetic flow meter accuracy is affected by non-uniform velocity profiles because magnetic flow meter algorithms assume that the voltage measurement at the electrode is representative of a uniform flow. In Stoker's study, it is clear that the velocity profile is still not completely uniform at ten diameters downstream of the elbow, and consequently, the accuracy of the meter is still being slightly affected. For this study, several meters were tested for the purpose of illustrating that magnetic flow meter technologies are affected by upstream disturbances to different degrees. It is anticipated that the results of this study will show the potential influence that one might expect when installing a magnetic flow meter downstream of an elbow. Of course, it is left up to the user to determine if these potential effects on accuracy are acceptable or not and whether a laboratory calibration in simulated piping is warranted to improve installed meter accuracy.

\section{CONCLUSION}

Electromagnetic flowmeters are a common and widely used type of flow meter. It is important that the installation and operation requirements for magnetic flow meters are understood. Magnetic flow meter manufacturers normally provide installation and operation guidelines; however, in most cases, the guidelines do not address all non-ideal flow conditions and their effect on accuracy. A meter with a more uniform magnetic field on the plane of the measurement electrodes will produce a signal 
that accurately accounts for variations in velocity due to upstream disturbances. One such situation is when the meter is rotated at different orientations in respect to an upstream pipe bend. The effects of meter orientation on accuracy were the focus of this project. Four different meters from four different manufacturers where tested at two orientations downstream of a short-radius elbow at several different locations and flows. Results showed a shift in meter performance when the meter is rotated between the two orientations EIP and EOP.

Some shifts in meter performance were observed at all locations downstream of the elbow during this study as seen in Table 1. The author's expected measurement accuracy shifts at locations CC, 1D, 3D, and 5D, but not anticipated at 10D. The cause of the shift in meter performance is suspected to be related to the sensitivity of the electrodes inside the meter in relation to the shape of the velocity profile. The results from this study should be considered when deciding where to install a magnetic flow meter because it is apparent that the upstream flow disturbance of a bend does significantly affect accuracy flow measurement performance. 


\section{REFERENCES}

Luntta, E., Halttunen, J. (1998). "The effects of velocity profile on Electromagnetic flow measurement." Sensors and Actuators., 16, 335-344

Miller, R. (1996). Flow Measurement Engineering Handbook 3rd Edition. McGraw-Hill Education, Page 15.23 .

Perry, J. (2014) "Installation effects of an Electromagnetic flow meter." SeaMetrics.

Stoker, D. M. 2011. Ultrasonic Flow Measurement for Pipe Installations with Non-Ideal Conditions. School of Civil and Environmental Engineering, Utah State University, Logan, UT

Thorn, R., Melling, A., Kochner, H., Haak, R., Husain, Z., \& Wass, D. ... (1999). Chapter 28. Flow Measurement. In The Measurement, Instrumentation and Sensors Handbook. S.I.: CRC Press. 
Table 1. Percent deviation shift for all locations and velocities

\begin{tabular}{|c|c|c|c|c|c|}
\hline Meter & $\begin{array}{l}\text { CC EIP to EOP } \\
\text { \% Deviation shift }\end{array}$ & $\begin{array}{l}\text { 1D EIP to EOP } \\
\text { \% Deviation shift }\end{array}$ & $\begin{array}{l}\text { 3D EIP to EOP } \\
\text { \% Deviation shift }\end{array}$ & $\begin{array}{l}\text { 5D EIP to EOP } \\
\text { \% Deviation shift }\end{array}$ & $\begin{array}{l}\text { 10D EIP to EOP } \\
\% \text { Deviation shift }\end{array}$ \\
\hline \multicolumn{6}{|l|}{$1 \mathrm{fps}$} \\
\hline A & $3.59 \%$ & $0.66 \%$ & $0.76 \%$ & $0.34 \%$ & $0.21 \%$ \\
\hline B & $3.07 \%$ & $0.97 \%$ & $0.19 \%$ & $0.14 \%$ & $0.31 \%$ \\
\hline C & $0.62 \%$ & $0.42 \%$ & $0.24 \%$ & $0.18 \%$ & $0.01 \%$ \\
\hline D & $0.66 \%$ & $0.46 \%$ & $0.36 \%$ & $0.60 \%$ & $0.47 \%$ \\
\hline \multicolumn{6}{|l|}{$4 \mathrm{fps}$} \\
\hline A & $3.75 \%$ & $0.78 \%$ & $0.17 \%$ & $0.07 \%$ & $0.41 \%$ \\
\hline B & $3.56 \%$ & $1.21 \%$ & $0.50 \%$ & $0.06 \%$ & $0.29 \%$ \\
\hline C & $0.76 \%$ & $0.18 \%$ & $0.10 \%$ & $0.06 \%$ & $0.11 \%$ \\
\hline D & $1.05 \%$ & $0.56 \%$ & $0.24 \%$ & $0.95 \%$ & $0.04 \%$ \\
\hline \multicolumn{6}{|l|}{$8 \mathrm{fps}$} \\
\hline A & $4.04 \%$ & $0.72 \%$ & $0.56 \%$ & $0.15 \%$ & $0.21 \%$ \\
\hline B & $4.33 \%$ & $1.25 \%$ & $1.18 \%$ & $0.06 \%$ & $0.35 \%$ \\
\hline C & $0.65 \%$ & $0.06 \%$ & $0.20 \%$ & $0.11 \%$ & $0.01 \%$ \\
\hline D & $0.97 \%$ & $0.26 \%$ & $1.31 \%$ & $0.36 \%$ & $0.32 \%$ \\
\hline \multicolumn{6}{|l|}{$12 \mathrm{fps}$} \\
\hline A & $4.18 \%$ & $0.68 \%$ & $0.26 \%$ & $0.21 \%$ & $0.05 \%$ \\
\hline B & $4.23 \%$ & $1.33 \%$ & $0.85 \%$ & $0.24 \%$ & $0.15 \%$ \\
\hline C & $0.83 \%$ & $0.03 \%$ & $0.14 \%$ & $0.16 \%$ & $0.01 \%$ \\
\hline D & $0.74 \%$ & $0.41 \%$ & $0.23 \%$ & $0.36 \%$ & $0.08 \%$ \\
\hline \multicolumn{6}{|l|}{$16 \mathrm{fps}$} \\
\hline A & $4.37 \%$ & $0.63 \%$ & $0.00 \%$ & $0.29 \%$ & $0.06 \%$ \\
\hline B & $4.40 \%$ & $1.38 \%$ & $0.61 \%$ & $0.39 \%$ & $0.00 \%$ \\
\hline C & $0.94 \%$ & $0.17 \%$ & $0.14 \%$ & $0.21 \%$ & $0.10 \%$ \\
\hline D & $1.40 \%$ & $0.06 \%$ & $0.01 \%$ & $0.16 \%$ & $0.20 \%$ \\
\hline
\end{tabular}


Table 2. Average of percent deviation shift for all locations and velocities

\begin{tabular}{|c|c|c|c|c|c|}
\hline Velocity & $\begin{array}{c}\text { CC EIP to EOP } \\
\text { AVG \% Deviation } \\
\text { shift }\end{array}$ & $\begin{array}{c}\text { 1D EIP to EOP } \\
\text { AVG \% Deviation } \\
\text { shift }\end{array}$ & $\begin{array}{c}\text { 3D EIP to EOP } \\
\text { AVG \% Deviation } \\
\text { shift }\end{array}$ & $\begin{array}{c}\text { 5D EIP to EOP } \\
\text { AVG \% Deviation } \\
\text { shift }\end{array}$ & $\begin{array}{c}\text { 10D EIP to EOP } \\
\text { AVG \% Deviation } \\
\text { shift }\end{array}$ \\
\hline $\mathbf{1} \mathbf{f p s}$ & $1.98 \%$ & $0.63 \%$ & $0.39 \%$ & $0.31 \%$ & $0.25 \%$ \\
\hline $\mathbf{4} \mathrm{fps}$ & $2.28 \%$ & $0.68 \%$ & $0.25 \%$ & $0.28 \%$ & $0.21 \%$ \\
\hline $\mathbf{8} \mathrm{fps}$ & $2.50 \%$ & $0.57 \%$ & $0.81 \%$ & $0.17 \%$ & $0.22 \%$ \\
\hline $\mathbf{1 2} \mathrm{fps}$ & $2.50 \%$ & $0.61 \%$ & $0.37 \%$ & $0.24 \%$ & $0.07 \%$ \\
\hline $\mathbf{1 6} \mathbf{f p s}$ & $2.78 \%$ & $0.56 \%$ & $0.19 \%$ & $0.26 \%$ & $0.09 \%$ \\
\hline $\mathbf{A V G}$ & $2.41 \%$ & $0.61 \%$ & $0.40 \%$ & $0.25 \%$ & $0.17 \%$ \\
\hline
\end{tabular}


Figure 1. Variations in pipe length for elbow test

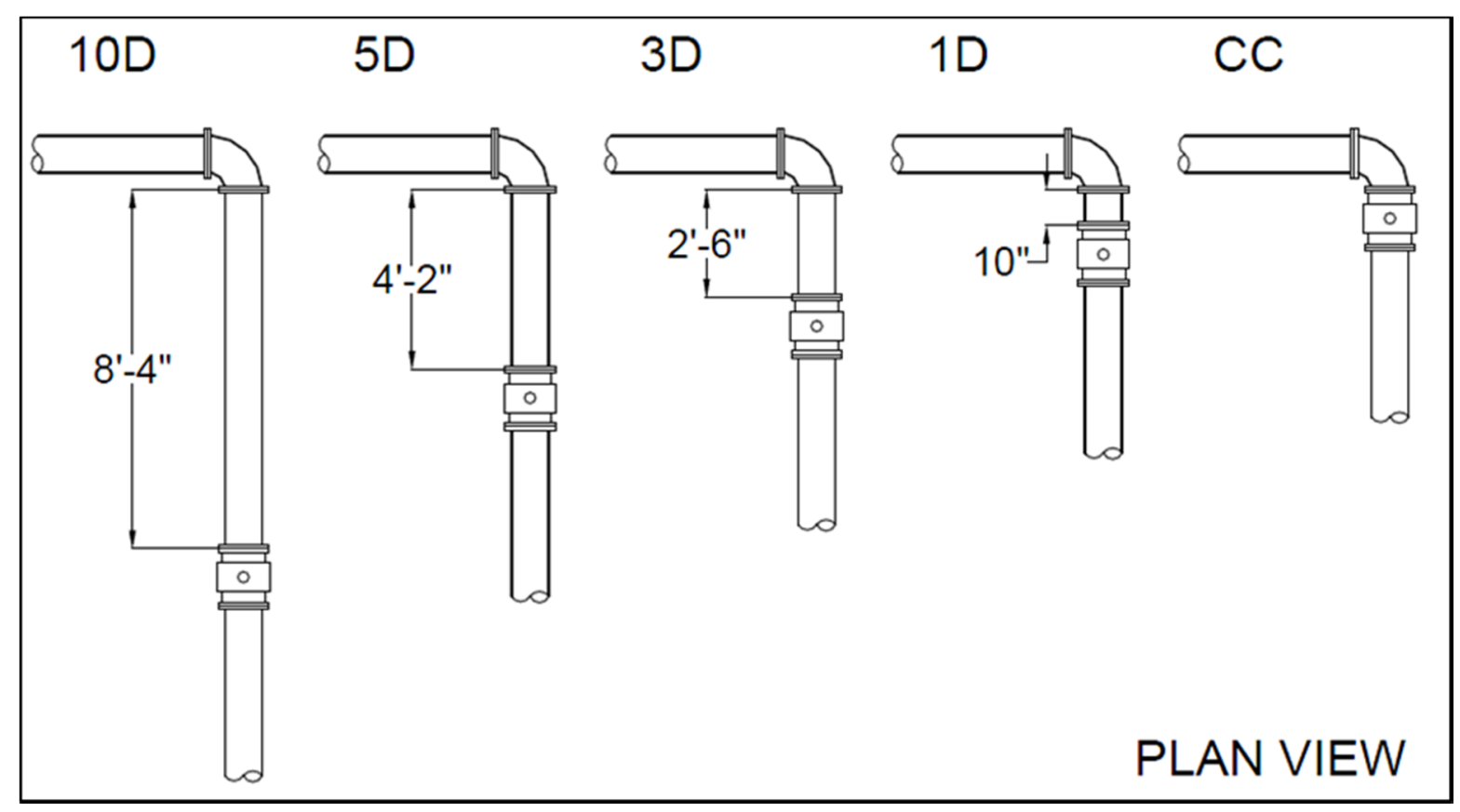


Figure 2. Meter orientation

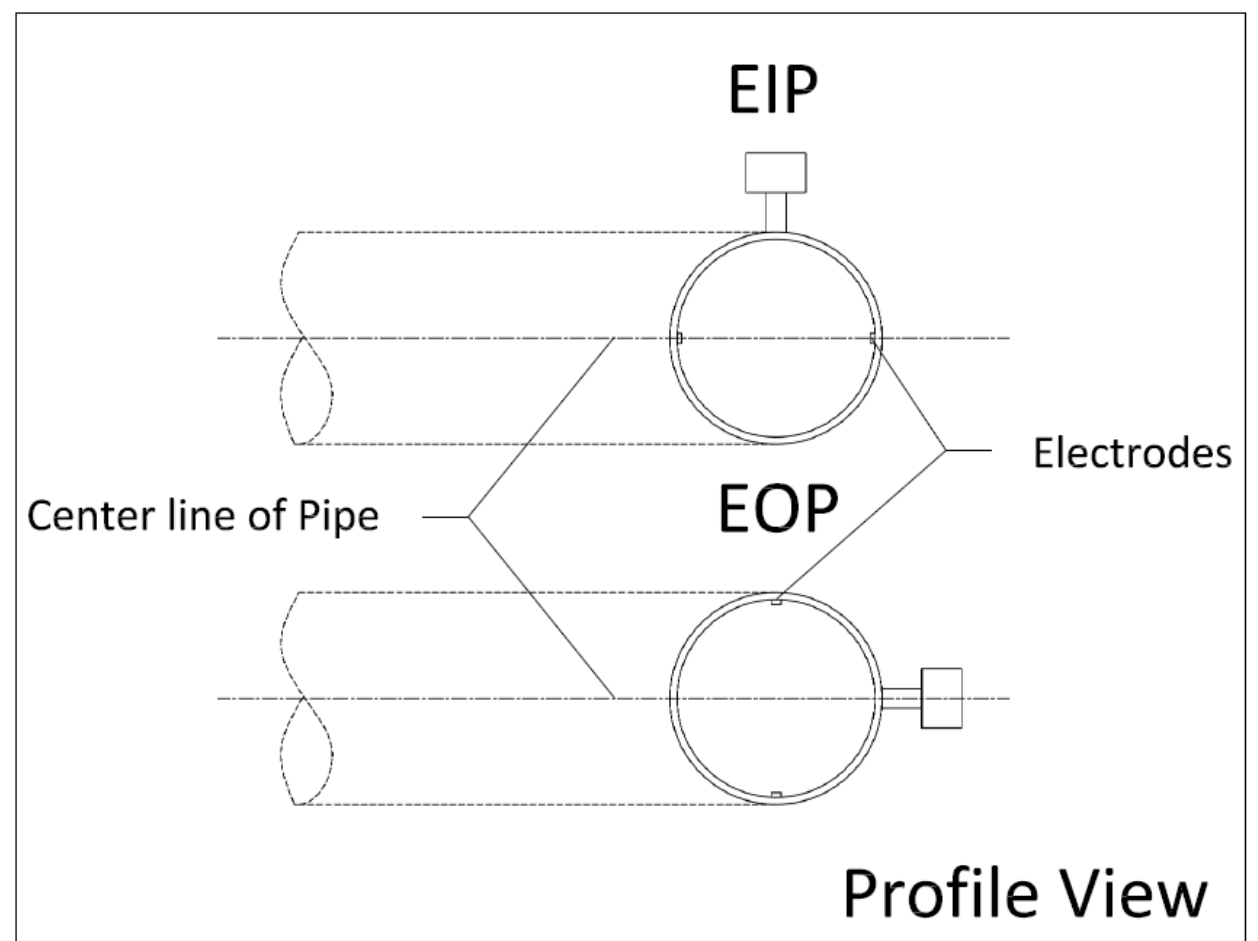


Figure 6. Meter D test plot

\section{Meter D Magnetic Flow Meter Data (Pulse, $\pm 1.00 \%$ )}

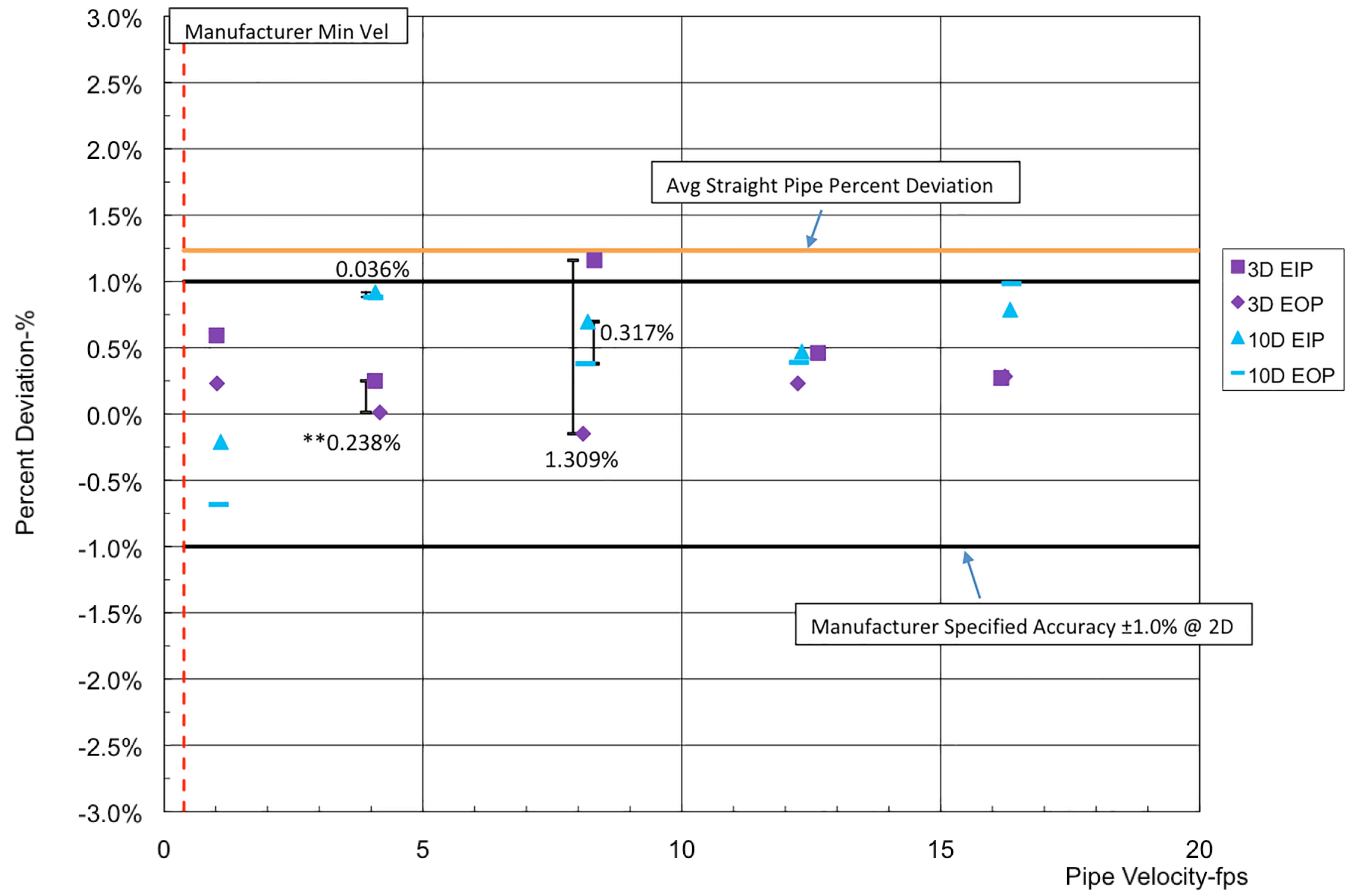




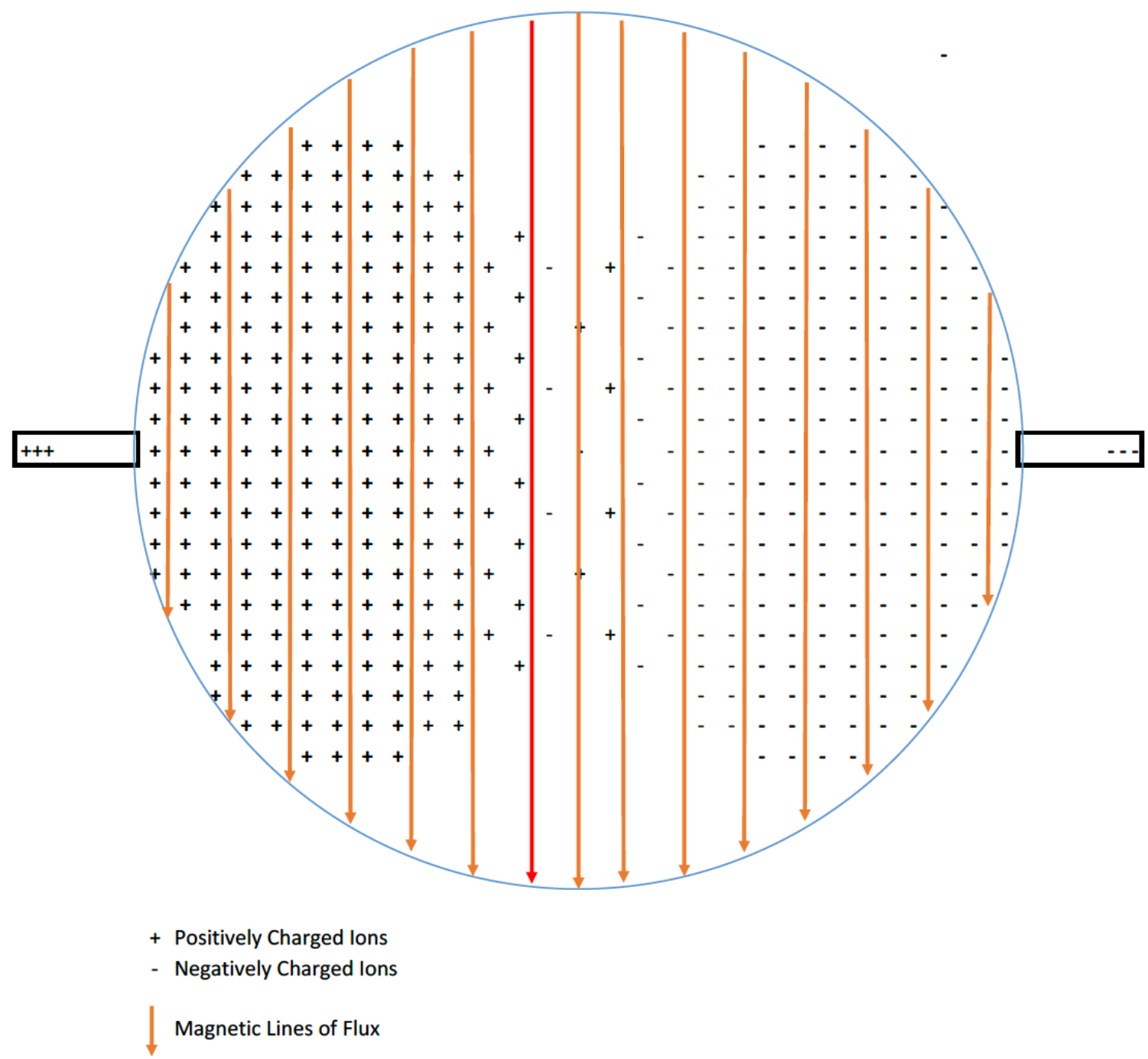

Figure 8. The Cross Section of a meter on the plane of the measurement electrodes with lines of magnetic flux drawn to show uniform magnetic field. The migration of lons shown in the magnetic field. 
Figure 9. Contours of fully-developed velocity profile $(\mathrm{Re}=500,000)$

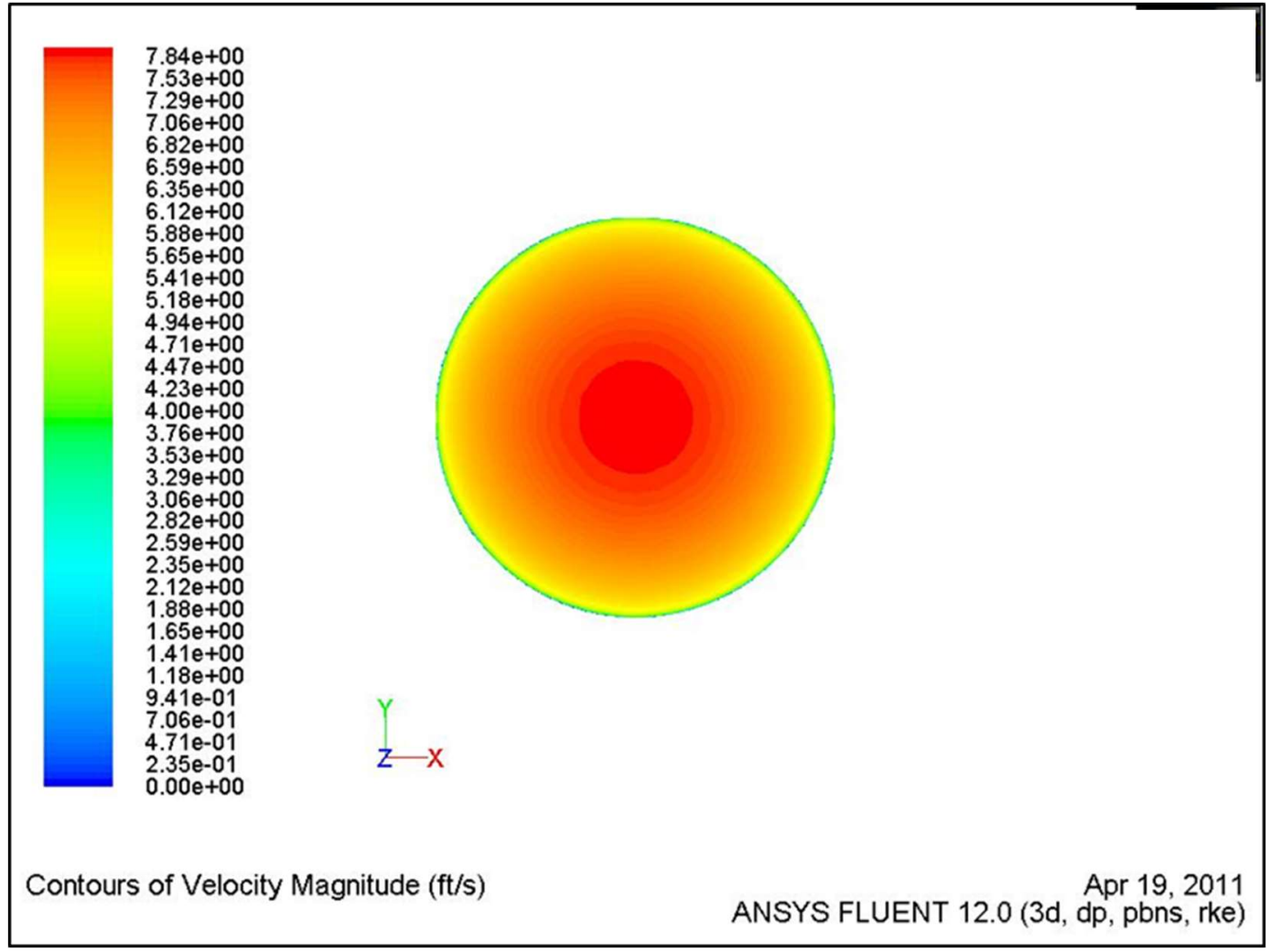


Figure 10. Contours of $\mathrm{X}$-velocity at $1.5 \mathrm{D}$ downstream $(\mathrm{Re}=500,000)$

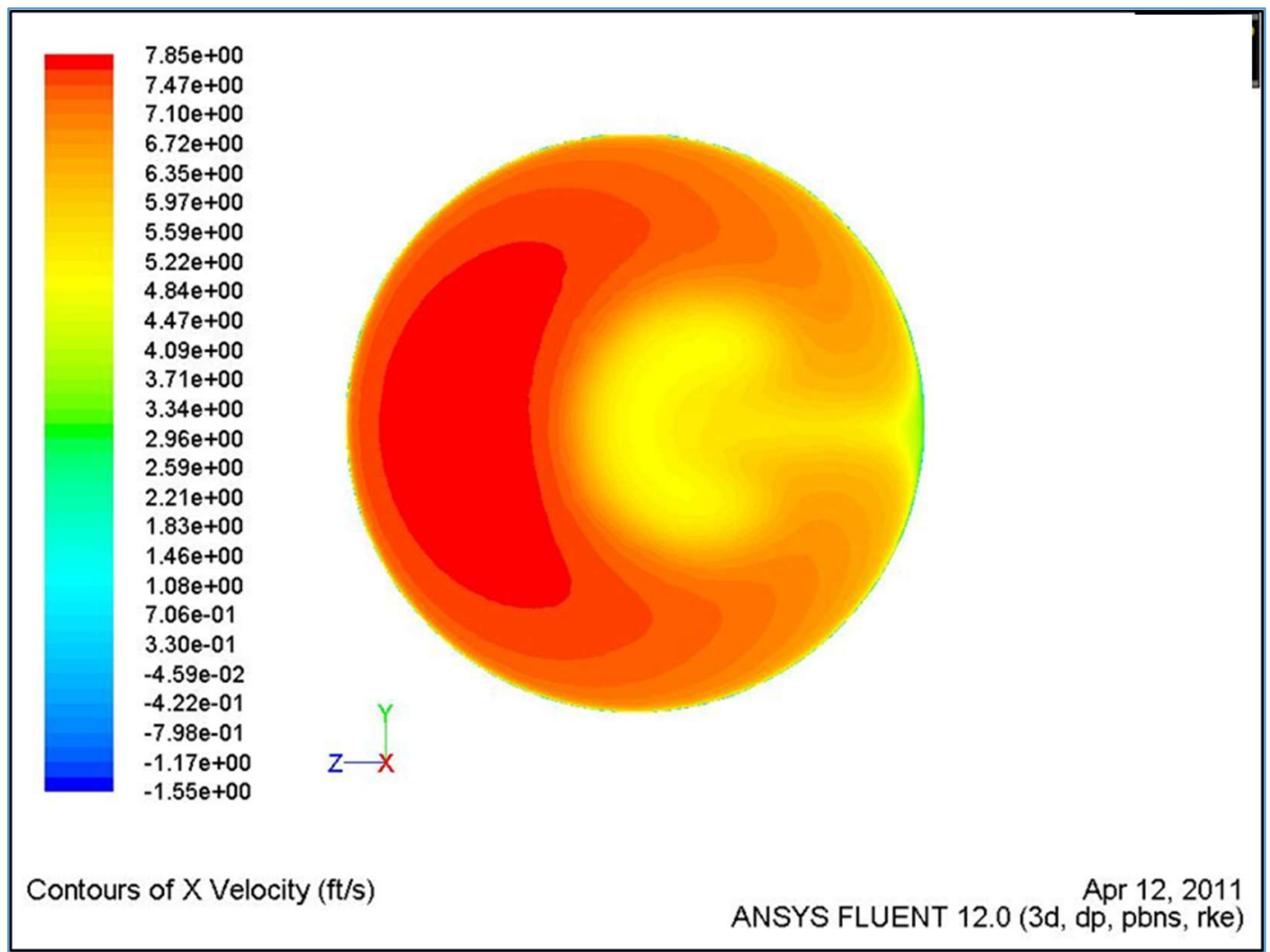


Figure 11. Contours of $X$-velocity at $10 \mathrm{D}$ downstream $(\mathrm{Re}=500,000)$

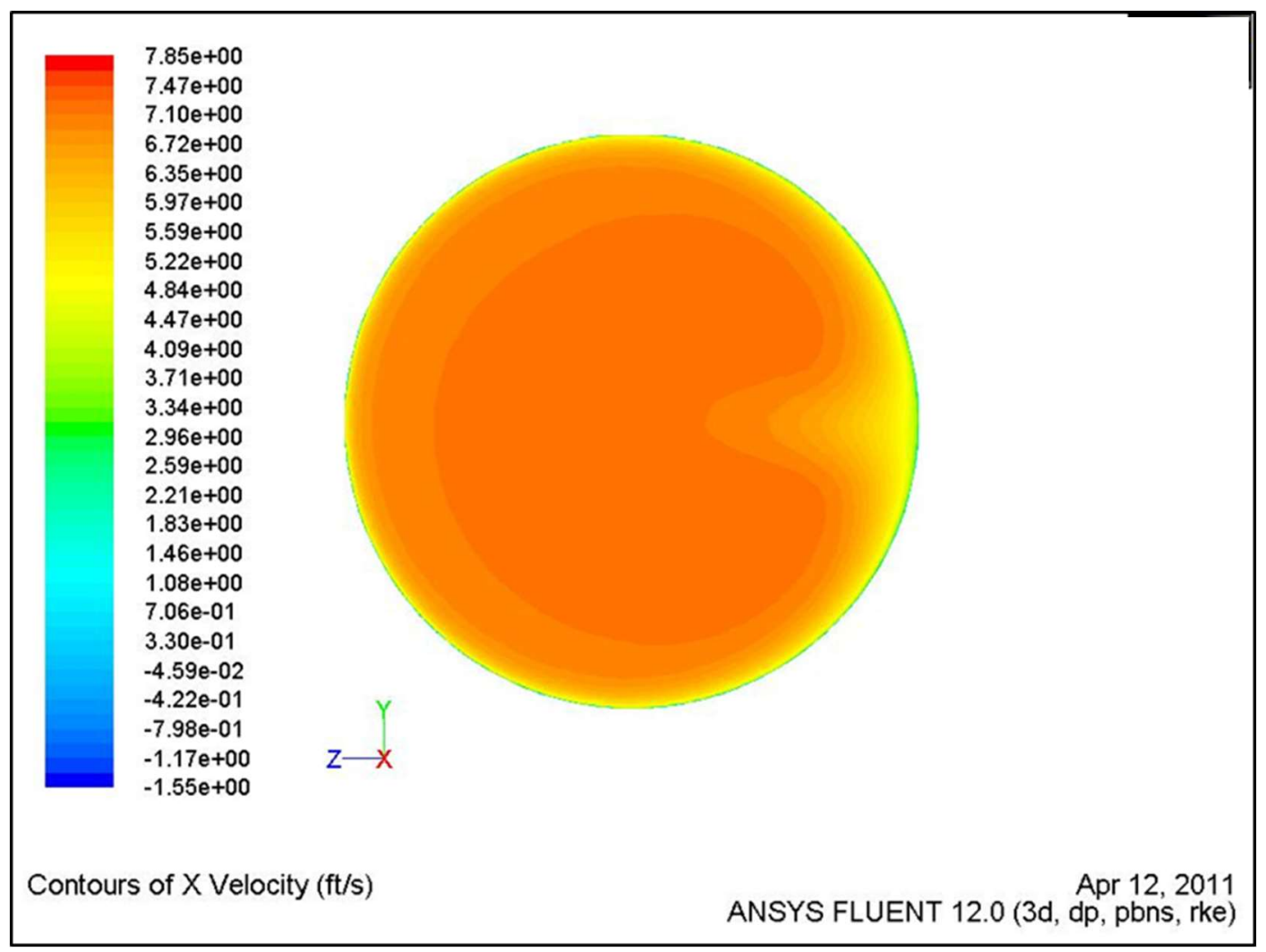

